\title{
A comparative analysis of an electronic exams versus paper exams between different gender of iraqi students
}

\author{
Marwa M. Ismail ${ }^{1}$, Bashar S. Bashar², Bashar B. Qas Elias ${ }^{3}$ \\ ${ }^{1,2}$ Department of Electrical Engineering Al Nisour University College, Iraq \\ ${ }^{3}$ School of Computer and Communication Engineering Universiti Malaysia Perlis (UniMAP), Malaysia
}

\begin{abstract}
Article Info
\section{Article history:}

Received Feb 7, 2020

Revised Apr 11, 2020

Accepted Apr 25, 2020

Keywords:

E-exam

MSQ, SQL server

NET Framework 4.5.

Paper exam

ABSTRACT

When students believe they can get smarter, they understand that effort makes them stronger. Therefore, they put in extra time and effort, and that leads to higher achievement. Besides that, the arrangement of question papers and answer sheets process for a high number of students takes a long time. In this paper, the sheet exam has been proposed to change into an electric exam (E-exam). This system depended on the client-server framework to convert the traditional exam environment into an electronic exam, providing multiple and different questions at the same time. In additions, kept the grades of students and providing them automatically. In this paper, Visual Studio and Microsoft SQL server have been proposed to develop the electronic exam. The questionnaire is made by distributed it among 30 students, and after the data analysis, the results have been collected have been represented a response rate of $100 \%$. It is recommended that, to take electronic exams and e-learning for students periodically. To improve their performance through continuous training on computerized exams and to increase the student's efficiency in this type of learning.
\end{abstract}

Copyright $@ 2020$ Institute of Advanced Engineering and Science. All rights reserved.

\section{Corresponding Author:}

Bashar S. Bashar,

Computer Engineering Techniques,

Al-Nisour University College,

Email: Bashar.s.eng@nuc.edu.iq

\section{INTRODUCTION}

Normally, exams can be a logistical nightmare which most teaching staff in educational institutions led to a few tests. This reflects negatively on the desire of some students to take more than one test during the semester [1-3]. Mostly, how to prepare and write high-quality exam questions and how to answer them are the most important issues that concern the teaching staff in the educational environment. As well as monitoring cases of fraud that may occur between students. This is followed by correcting the answers manually and announcing the results [4]. Recently, changing from a traditional examination to an electronic examination become an urgent necessity which represented a modern approach to education. By using E-exams, many common problems of the traditional exam can be solved for a high-quality exam [5]. There are four main goals for an e-exam process, as shown in Figure 1.

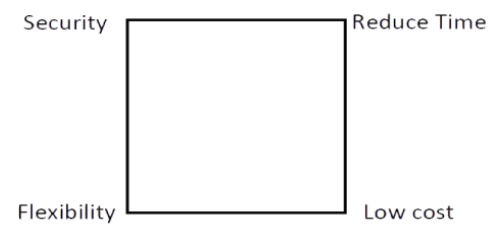

Figure 1. The square of E-exam 
From the above figure, it is observed that E-exams have many advantages over traditional exams such as a low cost, a considerable. Amount of paper is spent for question sets and student answer sheets, besides, a toner and hardware resources for printing/copying [6]. Hence, E-exam plays an important role in reducing the cost and maintaining the privacy of the exam [7-9]. E-exams can only be taken by access the computer networks in the labs. Each student gets an account, including the username and password that are only valid for the specified exam. At the end of the exam the results are submitted directly to the database to be processed and saved [10]. Results can be compared with paper examination results that evaluated by the teacher and providing a high degree of security [11-13], The E-exam reduces the time for writing questions, correcting papers, and printing the results [14]. It provides clear instructions to answer the questions in exams which reduces the ambiguous questions that weaken the tests' reliability. The long exams are more reliable than short exams because it contains a large number of variables. These exams are generally using Multiple Choice Questions (MCQ) [15, 16]. MCQ process takes less time compared to textual tests Is one of the main advantages of using the MCQ that are supported by electronic exams [17].

Over a wide range of time and by tested the student's ability to answer the questions, the exam was been classified into two categories; the first one is the hardcopy exam. This type of exam is performed using the paper format, and the answers have recorded manually [18], fifteen minutes are given to complete this examination. The electronic exam is the second one which is a new approach that has been currently used around the world. Computers are used at the exact location of the exam; the electronic examination system is used to answer the questions and gets the results [19, 20].

This study aims to compare the E-exam and paper exam for female and male students and study the system importance as the following: -

a) Ease of preparation and application review results are possible. Set a descending time for the test.

b) Economical as it saves effort, time, and money.

c) Can be applied at the same time to a large group of individuals or at different times and in different places.

d) Their results immediately after answering all questions.

The work in [21, 22] studied the implementation of a web-based examination system was presented. The system was developed using ASP.Net and Hypertext Markup Language (HTML), ASP.Net and C-sharp as interface program, connection with internet and SQL Server as database. The application was tested on the university intranet, and students were able to test run the application using some sample MSQ examination questions of some general courses.

The work in $[23,24]$ proposed the student's perception of a bring-your-own (BYO) the electronic computer-based examination system. Data were collected using preliminary studies $(\mathrm{n}=128)$, which included qualitative comments and Likert elements. The opinions of students and exam systems focus on laptops, and many of them are satisfied with the approach to conducting electronic exams in the classroom.

The work in [25] presents the design and user evaluation of a resilient e-Exam platform, draw upon the education and technology acceptance literature as a basis for evaluation. The approach also enables rich, constructed assessment tasks by providing authentic 'e-tools of the trade' software applications and a consistent operating system on each student's BYO laptop. Students undertook a sequence of practice, mid-term, and a final examination using the platform. It is observed that students were able to accept the networked edition of the e-exam system as being fit for purpose for undertaking supervised time-limited exams. Students gave reliability and usability ratings in line with previous off-line e-exam trial outcomes.

The work in [26] studied the electronic exam (e-Exam), as a perfect ability to test no longer only college students for the absence of a world general or a design structure. Has developed a system that can be adapted for most types of exams of computers in any institution with reliable security and integrity of results, as well as software implementation. The analysis of several these systems and the evaluation of problems and security errors led to the development of a new computer test system. The system was developed using a unified modeling language (UML) and implemented using HTML, PHP, and MySQL as a web application.

\section{E-EXAM AND DATA COLLECTION TOPOLOGY}

In this study, quantitative data has been used to explore the teachers and students experiences in e- Examination [27]. The results of this research-based on information obtained are collected manually by students [28]. The tests have been conducted in the computer engineering techniques department. The students are asked to evaluate their experiences in E-exam using organized questionnaires which they are delivered to each student personally. Several ways have been used to organize electronic exams. The system is used for essay and MSQ examinations [29]. The electronic exam included many questions in a specific period of time. These questions are stored in the database with the correct answers for all questions. The basic structure of the system is shown in Figure 2.

Indonesian J Elec Eng \& Comp Sci, Vol. 20, No. 1, October 2020 : 423 - 429 


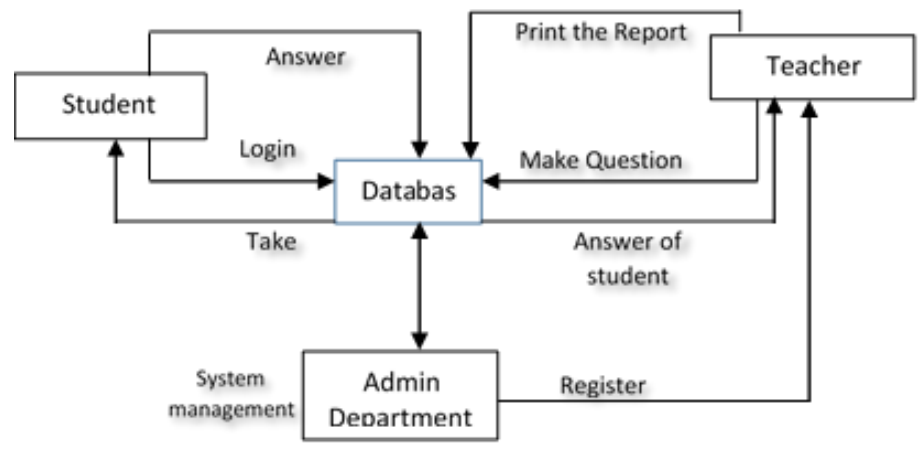

Figure 2. E-Exam system structure

The examination contains a set of questions prepared as an MCQ form. In this case, three groups of exams with five computers and one teacher for each group have been adopted as illustrated in Figure 3.

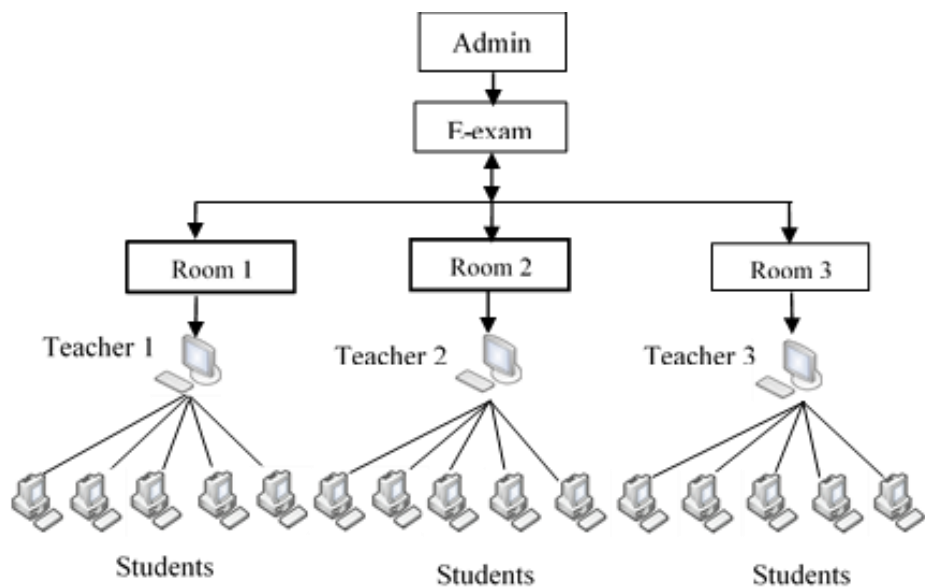

Figure 3. structure of E-exam

\section{THE PROCEDURE DESIGN}

\subsection{E-exam design for students}

The student represents the client and its system consists of two subsystems which are: -

a) E-Exam Package: Microsoft .NET Framework 4.5 was used to generate the E-exam package and it was selected because it delivers better performance, security, and reliability [30]. The NET Framework 4.5 is fully compatible with NET Framework 4 and Windows applications can be created by using a combination of Visual Basic and Microsoft .NET Framework 4.5.

b) E-Exam Browser: First, the student must register in the system with his relevant information, after the registration process the student login to the system with his ID, User Name and Password, if the login was failed the system will close automatically and the student must log in again and if the login was successful the questions in the database are uploaded to the student interface through the system, the student will select the answers and all the information will be sent to the database as shown in Figure 4(a).

\subsection{E-exam design for teachers}

The implementation of the database is achieved using a combination of visual studio 2012 and SQL server, The admin creates a username and password for each teacher and the teacher can see the questions related to his own material only, the degree will be calculated upon the correct answers and the teachers will be considered the test results directly, the server of the program will print the students degrees as shown in Figure 4(b) 


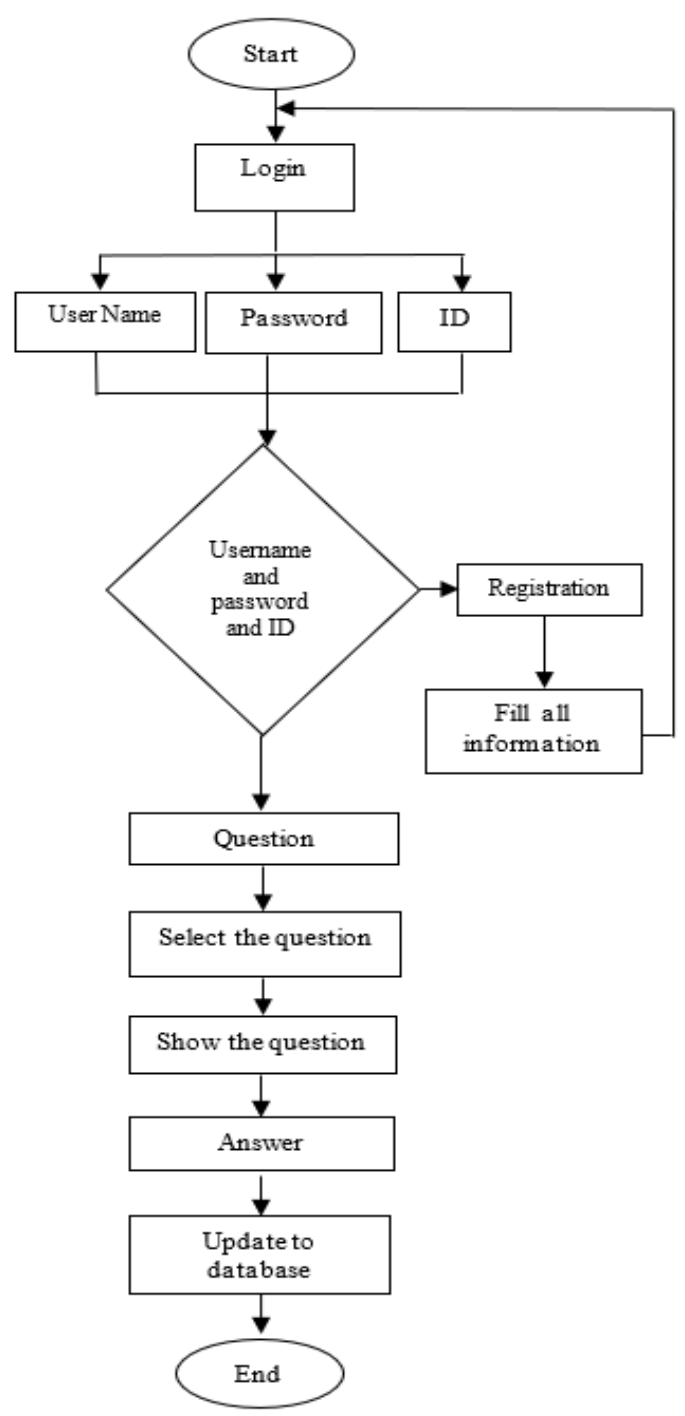

(a)
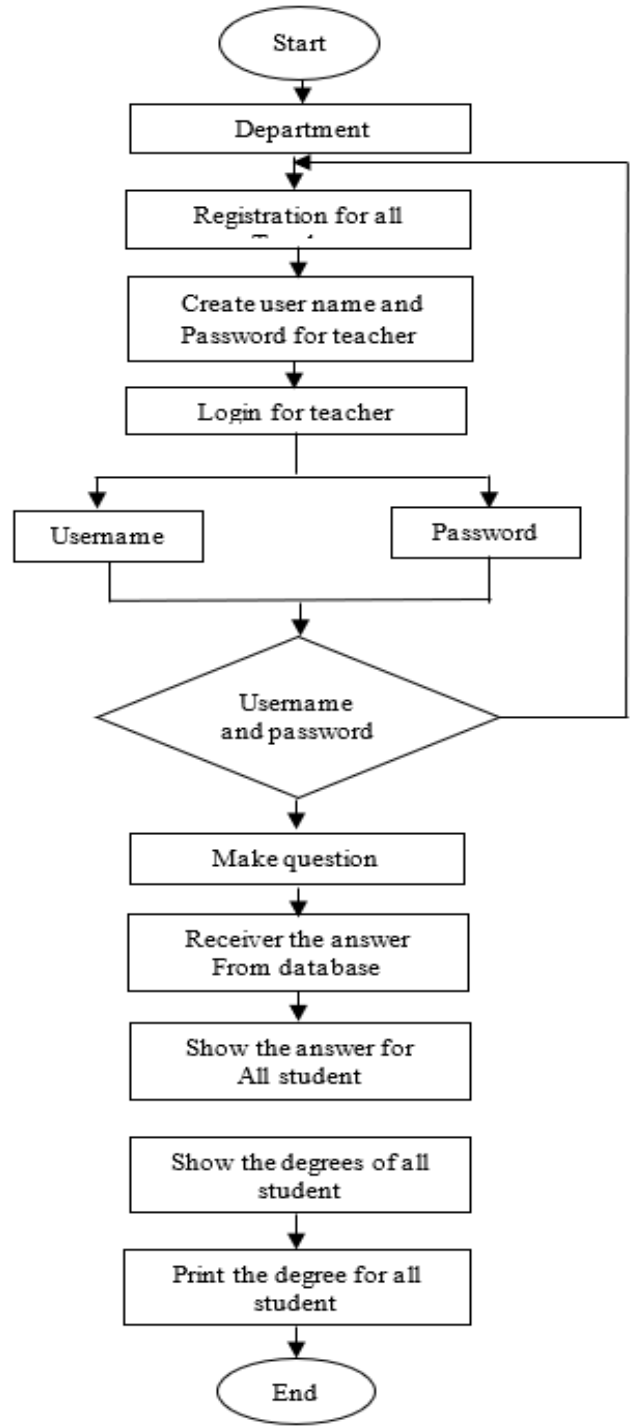

(b)

Figure 4(a) Flowchart of the study (b) Flowchart of the teacher

\section{THEORETICAL RESULT}

In this section, the supported course has been adopted using an electronic exam to guide the students about how to use the E-exam system. The total data set contains 900 degrees collected from 30 students. Each student answered 30 questions in the paper and the electronic exams. The exam is consisting of 15 multiple-choice questions; one degree for each question and the result has been calculated by the amount of the correct answers.

The results collected from the male and female students at different times have been presented as illustrated in figures below. The determined time of exam is $15 \mathrm{~m}$ it is observed that has some of the students in the female group have exceeded the time of the exam. For example, the female No. 1 in a third group has been finished the exam in $17.29 \mathrm{~m}$. On the other hand, female No. 5 in a first group took $18.15 \mathrm{~m}$ to finish it, as shown in Figure 5.

It is noted that extra time is the main problem needed to complete the exam. This problem can be eliminated by using the electronic exam as shown in Figure 6. Female students did not exceed the exam time because the program has been automatically closed the application, and the data have been stored database. Also eliminating the time that is required to collect the papers from students which represents a waste of time for the entire educational establishment. Besides that, some students from the female group took less time to complete the electronic exam than the paper exam, where the female No. 1 of the third group took time equal to 17:28 min to finish the paper exam and 10:19 min to finish the electronic exam. On the other hand, female No. 3 of the first group took time equal to 4:53 min to finish the paper exam and 13:03 min to finish the electronic exam. Also, the male group are suffering the same problem as in the female group during the paper test as shown in Figure 7. The results presented above show that a good impression to overcome the problem, as shown in Figure 8. 


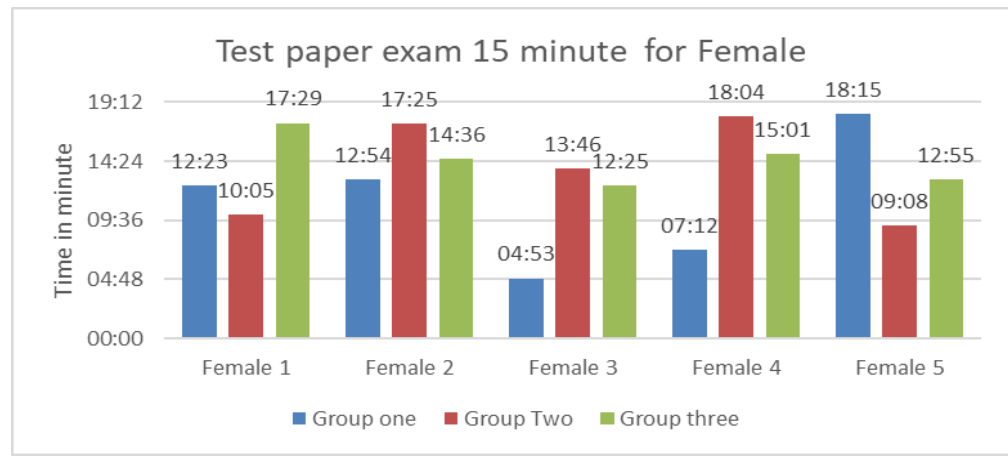

Figure 5. Statistical analyzes for paper test for female

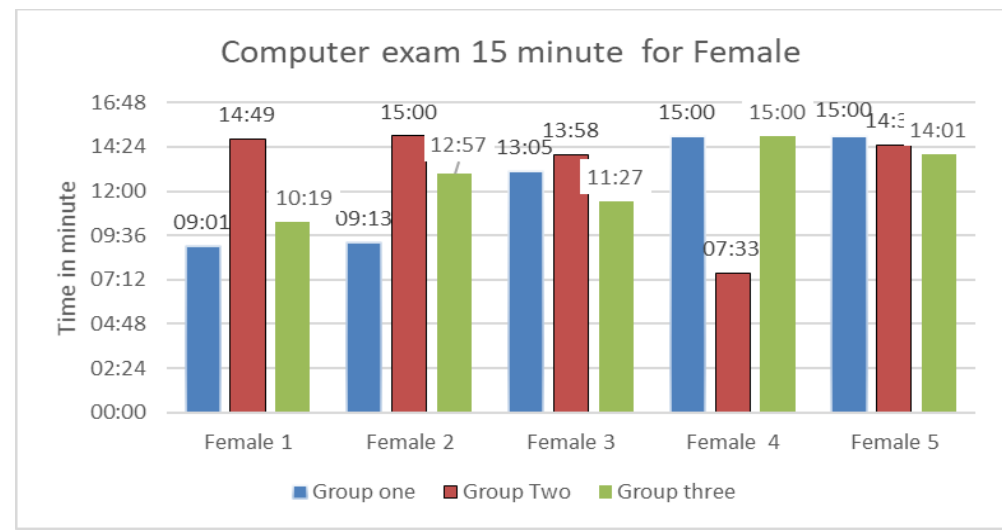

Figure 6. Statistical analyzes for computer test for female

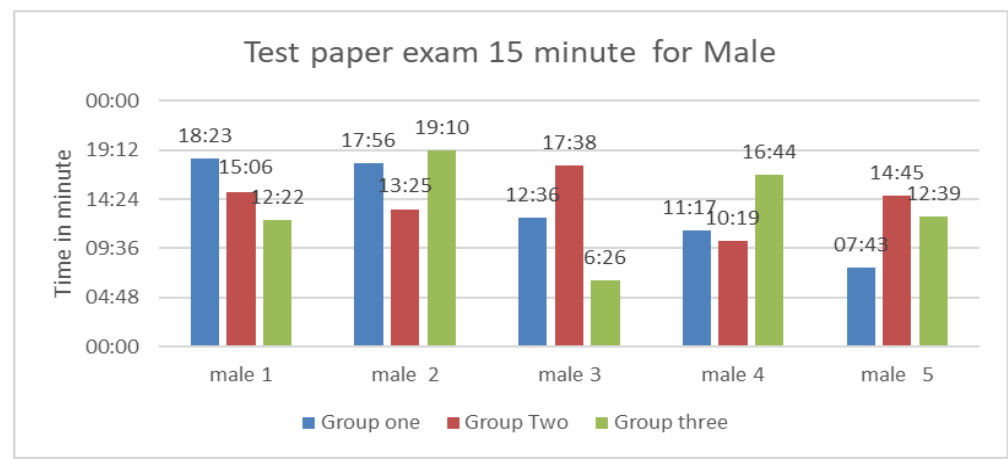

Figure 7. Statistical analyses for paper test for male

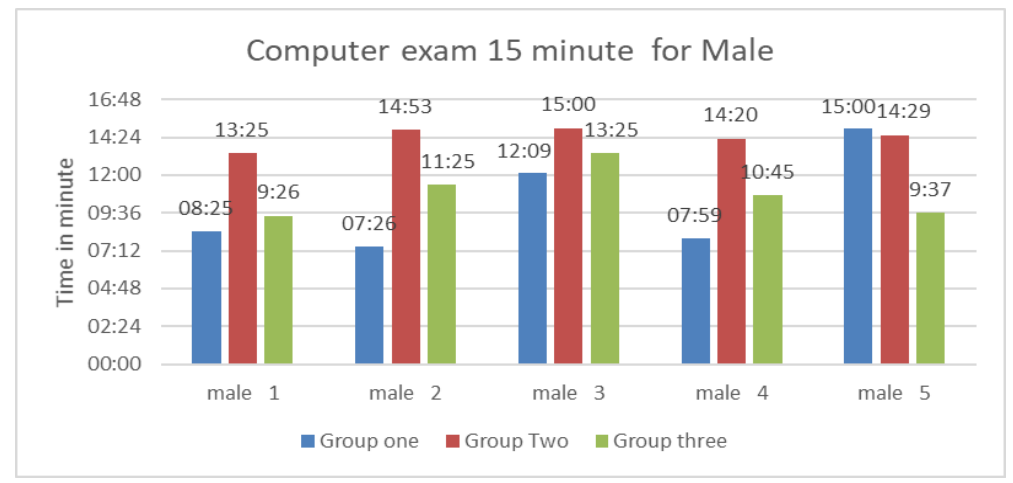

Figure 8. Statistical analyzes for computer test for male 
This section presents the data analysis results based on the difference in exceeded time between the paper test and computer test. A general picture of the participants is illustrated in Table 1. Also, in Table 2, the participants are divided into two main groups (female and male groups). Each group consisted of 30 students. The major group is divided into three subgroups with five students as shown in Table 1 . The time loss in the paper is 08:48 sec for female and 10:11 sec for male, while in computer test, the time has not to be exceeded.

Table 1 Exceeded Time between paper and computer tests for female

\begin{tabular}{|c|c|c|c|c|c|c|c|}
\hline \multirow{2}{*}{ Tests } & \multirow{2}{*}{$\mathrm{N}$} & \multirow{2}{*}{ M } & \multirow{2}{*}{$\mathrm{F}$} & \multicolumn{3}{|c|}{ exceeded Time for female } & \multirow{2}{*}{ Total time } \\
\hline & & & & Group one & Group Two & Group three & \\
\hline Paper test & 30 & 15 & 15 & $03: 15 \mathrm{~s}$ & $03: 04 \mathrm{~s}$ & $02: 29 \mathrm{~s}$ & $08: 48 \mathrm{~s}$ \\
\hline Computer test & 30 & 15 & 15 & 00:00 & 00:00 & 00:00 & 00:00 \\
\hline
\end{tabular}

Table 2 Exceeded Time between paper and computer tests for male

\begin{tabular}{|c|c|c|c|c|c|c|c|}
\hline \multirow{2}{*}{ Tests } & \multirow{2}{*}{$\mathrm{N}$} & \multirow{2}{*}{ M } & \multirow{2}{*}{$\mathrm{F}$} & \multicolumn{3}{|c|}{ exceeded Time for female } & \multirow{2}{*}{ Total time } \\
\hline & & & & Group one & Group Two & Group three & \\
\hline Paper test & 30 & 15 & 15 & $03: 23 \mathrm{~s}$ & $02: 38 \mathrm{~s}$ & $04: 10 \mathrm{~s}$ & $10: 11 \mathrm{~s}$ \\
\hline Computer test & 30 & 15 & 15 & 00:00 & 00:00 & 00:00 & 00:00 \\
\hline
\end{tabular}

Table 3 demonstrated that $16.6 \%$ of students prefer the computer in exams, while $83.3 \%$ of students do not want to use the computer in exams. $36.6 \%$ of the students agreed that the electronic exam makes the understanding of the question more difficult compared with $63.3 \%$ of the students disagreed that. Besides, $6.6 \%$ of students have difficulty in using the program, and $93.3 \%$ have no difficulty in use. Next, $10 \%$ of the students show that the time allocated for the electronic exam is enough, while $90 \%$ do not agree with that. On the other hand, $96.6 \%$ of students show the difficulty to solve the mathematical equations compared with $3.3 \%$ against that. Finally, $96.6 \%$ of students found that the presence of the teacher while taking the exam is necessary and, and $3.3 \%$ saw the opposite.

Table 3 Students' experience in e-Exam

\begin{tabular}{llllllll}
\hline \multirow{2}{*}{ No } & \multirow{2}{*}{ Question } & \multicolumn{2}{c}{ Total number } & \multicolumn{2}{c}{ Agree } & \multicolumn{3}{c}{ Disagree } \\
& & $\mathrm{M}$ & $\mathrm{F}$ & $\mathrm{N}$ & $\mathrm{M}$ & $\mathrm{F}$ & $\mathrm{N}$ \\
\hline 1 & Use the computer in exams? & 15 & 15 & 5 & 15 & 15 & 5 \\
2 & Difficult to understand questions? & 15 & 15 & 11 & 15 & 15 & 11 \\
3 & Difficult to use the program? & 15 & 15 & 2 & 15 & 15 & 2 \\
4 & The time allocated for E-exam is sufficient & 15 & 15 & 3 & 15 & 15 & 3 \\
5 & Difficult to solve the mathematical questions? & 15 & 15 & 29 & 15 & 15 & 29 \\
6 & The need for a teacher during the exam? & 15 & 15 & 18 & 15 & 15 & 18 \\
\hline
\end{tabular}

\section{CONCLUSION}

A comparative analysis of electronic exams versus paper exams between different gender students is presented in this paper. The first attempt to change the paper exam to an electronic exam has been rejected by $83.3 \%$ of students because of its difficulty of understanding the mathematical questions and the mechanism of using the program and computer. From the results obtained, it is observed that many benefits have been achieved by using the electronic exam in terms of effort, time, ease of preparation and possibility to attach an audio or video file in each question. The proposed questionnaire was as follows: $67 \%$ of female made progress in ending the exam in less time, while this percentage for male is up to (87\%). $63.3 \%$ of students do not have difficulty in understanding the questions of the program. On the other hand, $96.6 \%$ of students found it challenging to solve the mathematical questions. There is a positive outlook towards the use of the e-learning system and its benefits for current and future generations of students.

\section{REFERENCES}

[1] C. Zilles, M. West, and D. Mussulman, "Student behavior in selecting an exam time in a computer-based testing facility," in 2016 ASEE Annual Conference \& Exposition, p. 25896, 2016.

[2] R. Walker and Z. Handley, "Designing for learner engagement with computer-based testing," Research in learning technology, vol. 24, 2016. 
[3] C.-J. Shieh and L. Yu, "A study on information technology integrated guided discovery instruction towards students' learning achievement and learning retention," EURASIA Journal of Mathematics, Science and Technology Education, vol. 12, no. 4, pp. 833-842, 2016.

[4] N. A. Omoregbe, A. A. Azeta, A. Adewumi, and A. O. Oluwafunmilola, "Implementing an Online Examination System," in Proceedings of ICERI 2015 Conference, p. 55-61 2015.

[5] M. S. Al-Hakeem and M. S. Abdulrahman, "Developing a new e-exam platform to enhance the university academic examinations: The case of Lebanese French University," International Journal of Modern Education and Computer Science, vol. 9, no. 5, pp. 9, 2017.

[6] G. Sindre and A. Vegendla, "E-exams versus paper exams: A comparative analysis of cheating-related security threats and countermeasures," in Norwegian Information Security Conference, vol. 8, no. 1, pp. 34-45, 2015.

[7] G. Sindre and A. Vegendla, "E-exams and exam process improvement," in Norsk IKT-konferanse for forskning og utdanning, 2015.

[8] A. Rytkönen and V. Virtakoivu, "Comparative student experiences on electronic examining in a programming course-case C," in Proceedings of the 19th Koli Calling International Conference on Computing Education Research, pp. 1-10, 2019.

[9] H. Elbasri, A. Haddi, and H. Allali, "Improving e-learning by integrating a metacognitive agent," International Journal of Electrical \& Computer Engineering (2088-8708), vol. 8, 2018.

[10] A. Fluck et al., "eExam symposium: design decisions and implementation experience," in 11th IFIP TC 3 World Conference on Computers in Education, 2017.

[11] A. Koschmider and D. Buschfeld, "Shifting the process of exam preparation towards active learning: A crowdsourcing based approach," Informatik 2016, 2016.

[12] R. Jimoh, M. Yussuff, M. Akanmu, A. Enlkuomehin, and I. Salman, "Acceptability of computer based testing (CBT) mode for undergraduate courses in computer science," Journal of Science, Technology, Mathematics and Education (JOSTMED), vol. 9, no. 2, pp. 11-19, 2013.

[13] A. Fluck, O. S. Adebayo, and S. i. M. Abdulhamid, "Secure e-examination systems compared: case studies from two countries," The Journal of Information Technology Education: Innovations in Practice, vol. 16, pp. 107-125, 2017.

[14] Ö. Hüseyin and T. Özturan, "Computer-based and paper-based testing: Does the test administration mode influence the reliability and validity of achievement tests?," Journal of Language and Linguistic Studies, vol. 14, no. 1, pp. 67-85, 2018.

[15] H. Cheng, "Measuring the effect of amount of required student effort on exam performance," M.S. Thesis, University of Illinois at Urbana-Champaign, 2018.

[16] Y. Ozarslan and O. Ozan, "Self-assessment quiz taking behaviour analysis in an online course," European Journal of Open, Distance and e-learning, vol. 19, no. 2, pp. 15-31, 2016.

[17] S. H. Ali, P. A. Carr, and K. G. Ruit, "Validity and reliability of scores obtained on multiple-choice questions: Why functioning distractors matter," Journal of the Scholarship of Teaching and Learning, vol. 16, no. 1, pp. 1-14, 2016.

[18] S. Washburn, J. Herman, and R. Stewart, "Evaluation of performance and perceptions of electronic vs. paper multiple-choice exams," Advances in physiology education, vol. 41, no. 4, pp. 548-555, 2017.

[19] B. Basri, M. Assidiq, and U. Anatasya, "Linear congruent method (LCM) in testing system using clientserver model," IJISCS (International Journal of Information System and Computer Science), vol. 2, no. 1, pp. 51-58, 2018.

[20] T. Kattoua, M. Al-Lozi, and A. a. Alrowwad, "A review of literature on E-learning systems in higher education," International Journal of Business Management \& Economic Research, vol. 7, no. 5, pp. 754-762, 2016.

[21] O. A. Abass, O. B. Alaba, and A. A. Odumosu, "Design of an online examination information system for tertiary education," African Journal of Science and Nature, vol. 3, pp. 35-43, 2017.

[22] I. Salamah and M. A. Ganiardi, "Development of E-learning software based multiplatform components," Bulletin of Electrical Engineering and Informatics (BEEI), vol. 6, no. 3, pp. 228-234, 2017.

[23] O. F. Olawuyi, R. A. Tomori, and O. O. Bamigboye, "Students' Suitability of Computer Based Test (CBT) Mode for Undergraduate Courses in Nigerian Universities: A Case Study of University of Ilorin," International Journal Of Educational Sciences, vol. 20, no. 1-3, pp. 18-24, 2018.

[24] M. Hillier and N. Lyon, "Student experiences with a bring your own laptop e-Exam system in pre-university college," in Open Conference on Computers in Education, Springer, pp. 253-263, 2018.

[25] M. Hillier, S. Grant, and M. Coleman, "Towards authentic e-Exams at scale: Robust networked Moodle," Open Oceans: Learning Without Borders, 2018.

[26] O. T. Oluwatosin and D. D. Samson, "Computer-based test: security and result integrity," International Journal of Computer and Information Technology (ISSN: 2279 - 0764), vol. 02, no. 02, pp. 324-329, 2013.

[27] B. L. Putro, Y. Rosmansyah, and S. Suhardi, "An Intelligent agent model for learning group development in the digital learning environment (DLE): A systematic literature review," Bulletin of Electrical Engineering and Informatics (BEEI), vol. 9, no. 3, pp. 1159-1166, 2020.

[28] P. Hamsatu, G. Yusufu, and H. A. Mohammed, "Teachers' perceptions and undergraduate students' experience in E-exam in higher institution in Nigeria," Journal of Education and Practice, vol. 7, no. 23, pp. 158-166, 2016.

[29] H. Elbasri, A. Haddi, and H. Allali, "Design of a multi-agent system using the" MaSE" method for learners' metacognitive help," International Journal of Electrical and Computer Engineering, vol. 9, no. 3, p. 2033, 2019.

[30] M. N. F. 4.5., "https://www.microsoft.com/en-us/download/details.aspx?id=30653," 2019. 